\section{A unique case of durable complete remission after salvage with azacitidine and DLI for high risk flt-3 positive acute myeloid leukemia, following relapse 18 months post allogeneic stem cell transplant}

\author{
Claire Horgan, \\ Alexandros Kanellopoulos, \\ Shankara Paneesha, Bhuvan Kishore, \\ Richard Lovell, Emmanouil Nikolou \\ Hematology and Stem Cell \\ Transplantation Department, Heart of \\ England NHS Trust, Birmingham, UK
}

\begin{abstract}
A unique case of primary refractory FLT3-itd mutated acute myeloid leukemia in an elderly patient, who achieved completed morphological remission, and FLT3-itd negativity, following 9 cycles of azacitadine in combination with escalating doses of donor lymphocyte infusions following relapse 18 months post reduced intensity HLAA mismatch Campath conditioning allogeneic stem cell transplant.
\end{abstract}

\section{Introduction}

Acute myeloid leukemia (AML) remains a therapeutic challenge. Despite ongoing research, the standard therapy for AML has not changed significantly in the past four decades. With the identification of cytogenetic and molecular abnormalities, several promising therapeutic agents are currently being investigated. FLT3 mutation is a well-recognized target seen in $30 \%$ of the cytogenetically normal AML. FLT3 mutated AML, particularly those individuals who harbor the most common type of FLT3 mutation, the internal tandem duplication (ITD), provides a particular challenge for clinicians treating the condition as it has traditionally been associated with poor outcomes, with a median overall survival of 13.1 months. ${ }^{1}$

Patients with FLT3-itd mutated AML have been shown to benefit from allogeneic hematopoietic stem cell transplant (HSCT) to induce a potent antileukemic effect and overcome disease relapse in $1^{\text {st }}$ clinical remission, ${ }^{2}$ however, at an increased risk of relapse post-transplant, ${ }^{3}$ and outcomes following transplant relapse have been particu- larly poor. ${ }^{4}$ Efforts to develop protein kinase inhibitors, inhibiting mutated forms of the FLT3 receptor, have led to successive generations of FLT3 inhibitors, ${ }^{5}$ providing new hope for individuals with FLT3-itd mutations. The RATIFY trial concluded that the FLT3 inhibitor midostaurin increased overall survival in younger adult patients, when used in combination with intensive induction and consolidation therapy, ${ }^{6}$ however, randomized trials evaluating intensive chemotherapy with other FLT3 inhibitors, including lestaurtinib and sorafenib, failed to show an improvement in response rate and overall survival. ${ }^{7-10}$ Despite this, recent case reports have suggested that the FLT3 inhibitor sorafenib, used in combination with azacitadine and donor lymphocyte infusions in patients with FLT3-itd mutated AML, who have relapsed post-transplant, can be an effective approach that warrants further evaluation in clinical trials. ${ }^{11}$

\section{Case Report}

A 68-year-old lady, who was diagnosed with AML de novo, FLT3-itd positive (high ITD: wild type ratio-the FLT3 mutant-towild type allelic ratio reflects the fraction of leukemia cells that harbor the mutation) normal karyotype on $12^{\text {th }}$ February 2014, was referred for allogeneic stem cell transplantation in view of her high-risk disease. The patient had been previously well with no major comorbidities and had enjoyed regular exercise, particularly swimming, prior to diagnosis. Her disease was detected when a full blood count, sent by her GP as part of investigations for fatigue, demonstrated pancytopenia and a blast count of $30 \%$.

The patient had unfortunately been refractory to one course of DA-chemotherapy she had received on AML-17 but had an excellent response to FLAG-IDA, achieving complete remission in the bone marrow after her $1^{\text {st }}$ cycle. She had 1 brother, who was 66 years old and a heavy smoker and drinker, and since it was felt that he would not be an ideal candidate for a potential donor, an unrelated donor search was initiated following tissue typing.

The patient went on to complete a $2^{\text {nd }}$ course of FLAG-IDA and was in complete remission when she underwent an HLAmismatched (mismatch at HLA-A locus) reduced intensity-conditioned Fludarabine/ Busulphan for 2 days/Alemtuzumab $50 \mathrm{mg}$ over 2 days T-deplete matched unrelated donor allogeneic transplant, day $0=13 / 9 / 14$. Most studies show an advantage of alloHCT in first complete remission (CR1), with higher 3-5-year disease-free survival
Correspondence: Emmanouil Nikolousis, Hematology and Stem Cell Transplantation Department, Heart of England NHS Trust, Bordesley Green East, Birmingham, B9 5SS, United Kingdom.

Tel.: +30.01214243699.

E-mail: manos.nikolousis@heartofengland.nhs.uk

Key words: Acute myeloid leukemia, Flt-3 mutation, Azacitidine.

Acknowledgements: the authors wish to thank all nursing staff and BMT coordinators on ward 19 at Heart of England NHS Trust.

Contributions: $\mathrm{CH}$, manuscript writing; $\mathrm{AK}$, review of manuscript; SP, review of manuscript; BK, review of manuscript; RL, review of manuscript; EN, writing and review of manuscript.

Conflict of interest: the authors declare no potential conflict of interest.

Funding: none.

Received for publication: 26 July 2018 .

Accepted for publication: 15 November 2018.

This work is licensed under a Creative Commons Attribution-NonCommercial 4.0 International License (CC BY-NC 4.0).

(C) Copyright C. Horgan et al., 2019

Licensee PAGEPress, Italy

Hematology Reports 2019; 11:7800

doi:10.4081/hr.2019.7800

and lower relapse risk than with chemotherapy or autologous transplantation (autoHCT). Allo-HCT proceeding early after reaching CR1 seems to improve survival, rather than after several courses of consolidation chemotherapy. CMV status was negative (recipient), positive (donor), and blood groups A negative and A positive for the recipient and donor respectively. Conditioning for the transplant was complicated by Enterobacter and E.coli bacteremias which resolved following treatment with meropenem, and the transplant itself was generally well tolerated with no major toxicities, apart from mild nausea and diarrhea. The patient engrafted neutrophils on day +18 and platelet engraftment on day +20 and was subsequently discharged on day +26 following treatment for a further febrile episode.

The post-transplant period was fairly unremarkable with the patient suffering from mild, grade 1, skin graft versus host disease (GVHD) according to NIH criteria, which started 6 weeks post transplant and responded to topical steroids, and clostri- 
dium difficile diarrhea 2 months post transplant which resolved with oral vancomycin. Her 3-month bone marrow aspirate and trephine demonstrated $100 \%$ donor chimerism in the whole sample and $99 \%$ in CD3+ $\mathrm{T}$ cells, and her ciclosporin was gradually tapered from January 2015. The patient continued to have ongoing diarrhea, between 3-4 episodes per day, and underwent a flexible sigmoidoscopy in February 2015, which showed inflammation but no evidence of gut GVHD on biopsy. She continued to remain well over subsequent months and after a slow taper, her ciclosporin was stopped on $31^{\text {st }}$ June 2015. At 1-year post transplant, the patient was doing very well with only mild chronic skin GVHD (no sclerodermatous features, no mouth/eye/vaginal involvement) that was well-controlled with topical creams. Her lung function and echo at 1 year proved stable pulmonary and cardiac function respectively, and she was commenced on the vaccination program as per standard protocol. She continued to be monitored on a monthly basis and her clinical course over subsequent months remained uneventful.

\section{Relapse}

Despite this, when the patient attended clinic on 5/2/16 (18 months post transplant) she was alarmingly noted to have a significant reduction in Cher neutrophil count, so a viral screen for parvovirus, CMV, EBV, Adenovirus, HHV 6 and HHV 8 was sent and an urgent bone marrow arranged. Unfortunately, the bone marrow confirmed relapsed disease, with $20 \%$ blasts detected in the marrow flt-3 ITD positive and normal cytogenetics while a mixed chimerism was eatablished with $48 \%$ donor in the whole sample and $92 \%$ donor in the CD3+ T cell fraction. 2 months earlier she exhibited full chimera in both whole blood and $\mathrm{T}$ cells. She was commenced on azacitadine 75 $\mathrm{mg} / \mathrm{m}^{2}$ for 7 days, with a plan to have her $1^{\text {st }}$ donor lymphocyte infusion (DLI) after 2 cycles and access to AC220 and Crenolanib was applied for on a compassionate basis. Compassionate access to AC220 and Crenolanib was declined but she tolerated her $1^{\text {st }} 2$ cycles of azacitadine very well. Her chimerism post these 2 cycles was $53 \%$ and 91\% for whole blood and $\mathrm{T}$ cells respectively, and she had her $1^{\text {st }}$ DLI on 14/4/16 at a dose of $1 \times 10^{6} \mathrm{CD} 3+$ cells $/ \mathrm{kg}$. During that time she remained cytopenic and required red cell and platelet transfusion.

The patient proceeded with cycles 3 and 4 azacitadine and received her $2^{\text {nd }}$ DLI, at a dose of $5 \times 10^{6} \mathrm{CD} 3$ cells $/ \mathrm{kg}$ on $16 / 6 / 16$. (table 1 for subsequent timeline of blood chimerism results). She proceeded with monthly cycles of azacitadine and had her $3^{\text {rd }}$ DLI on $26 / 8 / 16$ at a dose of $1 \times 10^{7} \mathrm{CD} 3$ cells $/ \mathrm{kg}$ (Table 1$)$. On the $31^{\text {st }}$ September 2016 the patient attended clinic complaining of ongoing gastrointestinal symptoms and, since these were attributed to her azacitadine, her dose was reduced by $50 \%$ and the $9^{\text {th }}$ cycle was started 1 week later than scheduled. Unfortunately following this cycle, she developed gram-negative sepsis with E.coli requiring a brief intensive care admission for inotropic support. She recovered well and a bone marrow aspirate and trephine on 6/12/16, post 9 cycles of azacitadine and 3 doses of DLI, demonstrated complete morphological remission with FLT3-itd negativity. Following this, the patient has had no further treatment and continues to be monitored on a monthly basis in transplant clinic. She undergoes regular blood chimerism monitoring and her latest on $10 / 4 / 18$, almost 4 years postoriginal transplant and over 2 years following relapse, continues to demonstrate $100 \%$ donor chimerism in both whole blood and CD3+ T cells.

\section{Discussion}

FLT3-ITD mutations are associated with an inferior response to salvage therapy and a rapidly fatal progression at relapse both after chemotherapy and allogeneic stem cell transplantation. ${ }^{12}$ A number of FLT3 kinase inhibitors are in development and have been evaluated in patients with FLT3 mutated AML but none post allogeneic stem cell transplantation. Several mechanisms of resistance to FLT3-TKIs have been proposed and there is no evidence to a potent GvL effect in patients with high allelic ratio. ${ }^{13}$ Most prominently, the acquisition of mutations in the ATP-binding pocket of FLT3 inducing clinical resistance to FLT3 inhibitors has now been reported. ${ }^{14}$ We do not systemically evaluate the patients at relapse for the development of such mutation. An increasing allelic ratio with increasing rates of refractory disease has an obvious tendency to translate into decreasing CR rates. These findings underline the biological importance of specific FLT3 molecular characteristics in FLT3-ITDpositive AML. ${ }^{15}$

This unique case describes a patient with primary refractory FLT3-itd mutated AML with high ratio who relapsed 18 months post transplant and has achieved complete morphological remission, which has been sustained for 22 months since stopping therapy, with azacitadine and donor lymphocyte infusions only. To our knowledge, there are no other cases of this type, being FLT3-itd positive and refractory to DA initially, and subsequently have relapsed post transplant, who have achieved such long-lasting remission following treatment with this combination alone. The fact that relapse occurred more than 12 months post allogeneic stem cell transplant could have contributed to the positive outcome with the use of Azacitidine and DLI while low disease kinetics enabled the establishment of full donor chimerism and subsequent remission.

The combination of DLI and azacitadine has been explored in the treatment of AML relapse post transplant, but less that $20 \%$ of patients have achieved durable disease control, ${ }^{16}$ and the 1 patient reported in this data with the FLT3-itd mutation who achieved complete remission relapsed after 126 days.

\section{Conclusions}

Our case highlights that a sustained complete remission with DLI and azacitadine alone is possible, even in patients who have high risk disease and offers hope to some individuals in this situation, particularly in scenarios when access to novel agents is restricted or not tolerated.

Table 1. Timeline of blood chimerism results and relation to treatment.

\begin{tabular}{lccc} 
Date & $\begin{array}{c}\text { Treatment } \\
\text { stage }\end{array}$ & $\begin{array}{c}\text { Chimerism whole } \\
\text { blood, } \%\end{array}$ & $\begin{array}{c}\text { Chimerism CD3 } \\
\text { T-cell fraction, \% }\end{array}$ \\
\hline $11 / 4 / 16$ & Post $2 \times$ aza & 53 & 91 \\
$21 / 4 / 16$ & Post $2 \times$ aza, $1 \times$ DLI & 81 & 98 \\
\hline $16 / 6 / 16$ & Post $4 \times$ aza, $2 \times$ DLI & 62 & 96 \\
$15 / 7 / 16$ & Post $5 \times$ aza, $2 \times$ DLI & 88 & 99 \\
\hline $28 / 11 / 16$ & Post $9 \times$ aza, $3 \times$ DLI & 100 & 100 \\
$24 / 2 / 17$ & No further treatment & 100 & 100 \\
\hline $10 / 7 / 18$ & No further treatment & 100 & 100 \\
\hline
\end{tabular}

aza, azacitadine; DLI, donor lymphocyte infusion.*Second DLI given day prior to sample. 


\section{References}

1. Röllig C, Bornhäuser $\mathrm{M}$, Thiede $\mathrm{C}$, et al. Long-term prognosis of acute myeloid leukemia according to the new genetic risk classification of the European LeukemiaNet recommendations: evaluation of the proposed re-porting system. J Clin Oncol 2011;29: 2758-65.

2. Brunet S, Labopin M, Esteve J, et al. Impact of FLT3 internal tandem duplication on the outcome of rela-ted and unrelated hematopoietic transplantation for adult acute myeloid leukemia in first remission: a retro-spective analysis. J Clin Oncol 2012;30:735-41.

3. Medeiros BC, Tian L, Robenson S, et al. European LeukemiaNet classification intermediate risk-1 cohort is associated with poor outcomes in adults with acute myeloid leukemia undergoing allogeneic hemato-poietic cell transplantation. Blood Cancer J 2014;4: e216.

4. Bejanyan N, Weisdorf DJ, Logan BR, et al. Survival of patients with acute myeloid leukemia relapsing af-ter allogeneic hematopoietic cell transplantation: a center for international blood and marrow transplant re-search study. Biol Blood Marrow Transplant 2015;21:4549.

5. Grunwald MR, Levis MJ. FLT3 tyrosine kinase inhibition as a paradigm for targeted drug development in acute myeloid leukemia. Semin Hematol 2015;52:193-9.
6. Stone RM, Mandrekar S, Laumann C, et al. Midostaurin, a multi-targeted kinase inhibitor, improves ove-rall survival when added to standard chemotherapy in adults age $18-60$ with FLT3 mutant acute myeloid leukemia (AML): results from a randomized, prospective, placebo-controlled, doubleblind trial, CALGB 10603/RATIFY. Blood 2015;126.

7. Levis M, Ravandi F, Wang ES, et al. Results from a randomized trial of salvage chemotherapy followed by lestaurtinib for patients with FLT3 mutant AML in first relapse. Blood 2011;117: 3294-330.

8. Knapper S, Russell N, Gilkes A, et al. A randomised assessment of adding the kinase inhibitor lestaurtinib to 1st-line chemotherapy for FLT3-mutated AML. Blood 2017;129:1143-54.

9. Serve H, Krug U, Wagner R, et al. Sorafenib in combination with intensive chemotherapy in elderly pa-tients with acute myeloid leukemia: results from a randomized, placebo-controlled trial. J Clin Oncol 2013;31:3110-8.

10. Rollig C, Serve H, Huttmann A, et al. Addition of sorafenib versus placebo to standard therapy in patients aged 60 years or younger with newly diagnosed acute myeloid leukaemia (SO-RAML): a multicentre, phase 2, randomised controlled trial. Lancet Oncol 2015;16: 1691-9.

11. Campregher PV, Pinto de Massos VR, et al. Successful treatment of post-transplant relapsed acute mye-loid leukemia with FLT3 internal tandem duplication using the combination of induction chemotherapy, donor lym-phocyte infusion, sorafenib and azacitidine. Report of three cases. Einstein (São Paulo) 2017; 15:355-8.

12. Gilliland DG, Griffin JD. The roles of FLT3 in hematopoiesis and leukemia. Blood 2002;100:1532-42.

13. Abu-Duhier FM, Goodeve AC, Wilson GA, et al. FLT3 internal tandem duplication mutations in adult acute myeloid leukaemia define a high-risk group. Br J Haematol 2000;111:190-5.

14. Rollig C, Serve H, Huttmann A, et al. Study Alliance Leukaemia. Addition of sorafenib versus placebo to standard therapy in patients aged 60 years or younger with newly diagnosed acute myeloid leukaemia (SO-RAML): a multicentre, phase 2, randomised controlled trial. Lancet Oncol 2015;16:1691-9.

15. Kottaridis PD, Gale RE, Frew ME, et al. The presence of a FLT3 internal tandem duplication in pa-tients with acute myeloid leukemia (AML) adds important prognostic information to cytogenetic risk group and response to the first cycle of chemotherapy: analysis of 854 patients from the United Kingdom Medical Research Council AML 10 and 12 trials. Blood 2001;98:1752-9.

16. Schroeder T, Czibere A, Platzbecker U, et al. Azacitidine and donor lymphocyte infusions as first salvage therapy for relapse of AML or MDS after allogeneic stem cell transplantation. Leukemia 2013;27:1229-35. 